\title{
Amor ou Desejo Mimético: \\ A narrativa CAMiliana SOB UMa nOVa PERSPeCtiva.
}

Ana Luísa Patrício Campos de Oliveira ${ }^{1}$

Resumo: Ao falarmos de Camilo Castelo Branco, uma das primeiras imagens que fazemos é a de romancista passional cujas histórias versam, em geral, sobre o amor, um sentimento puro e profundo, idealizado à moda romântica. Tal conceito acerca da ficção camiliana muito se deve em função da essencialidade passional atribuída pela crítica tradicional à obra do escritor de São Miguel de Seide. Entretanto, ao operarmos uma leitura despojada dos correntes estereótipos, notamos a presença indubitável de outros agentes, talvez mais indissociáveis à narrativa camiliana do que aqueles tradicionalmente abordados, tais como o desejo. Vale ressaltar que, no presente estudo, tomamos o desejo segundo a perspectiva de René Girard, em Mensonge Romantique et Vérité Romannesque. Para Girard, na literatura romanesca sobretudo, o desejo estrutura-se em uma relação triangular, na qual entre o sujeito e o objeto almejado está, sempre, um terceiro elemento, seja ele um modelo adquirido ou um mediador externo. Assim posto, nesta apreciação, buscar-se-á elaborar uma nova perspectiva acerca da narrativa camiliana, um discurso no qual o desejo mimético aflora como mote fulcral. Para tanto, valer-nos-emos de dois romances centrais para a discussão: Onde está a Felicidade? e Um Homem de Brios, ambos de 1856.

Résumé: Quand on parle sur Camilo Castelo Branco, la première image que l'on fait est d'un romancier de histoires d'amour, un sentiment pur et profond, idéalisé suivant le goût romantique. Ce concept à propos de la fiction camilienne est dû, particulièrement, à cause de la constituition passionnelle attribuée par la critique traditionnelle à l'oeuvre de l'écrivain de São Miguel de Seide. Toutefois, quand on opère une lecture destituée des ces stéréotypes, nous pouvons noter la présence d'autres aspects, peut-être plus caractéristiques des romans camiliens que ceux traditionnellement analysés, comme le désire. Il faut mettre en évidence que, dans cette étude, nous comprenos le désire sous la perspective de Réné Girard, énoncée en Mensonge Romantique et Vérité Romannesque. Selon Girard, dans la littérature romanesque surtout, le désire a une estructure triangulaire, dans laquelle entre le sujet et l'objet souhaité il y a, toujours, un troisième element, soit il un modèle détenu ou un médiateur externe. De cette manière, dans cette appréciation, nous nous proposons à élaborer une nouvelle perspective à propos du récit camilien, une étude dans laquelle le désire mimétique surgit comme un thème essentiel. Pour bien faire cette analyse, deux romans centraux seront pris comme corpus : Onde está a Felicidade? et Um Homem de Brios, tous les deux de 1856.

Palavras-chave: Camilo Castelo Branco, Réné Girard e Desejo Mimético. Mots clés : Camilo Castelo Branco, Réné Girard et Désiré Mimétique.

\footnotetext{
${ }^{1}$ Doutoranda do Programa de Estudos Comparados de Literaturas de Língua Portuguesa do Departamento de Letras Clássicas e Vernáculas da Faculdade de Filosofia, Letras e Ciências Humanas da Universidade de São Paulo.
} 
Ao falarmos de Camilo Castelo Branco, uma das primeiras imagens que fazemos é a de romancista passional cujas histórias versam, em geral, sobre o amor, um sentimento que seria genuíno e profundo, fulcral para a estruturação da diegese. Tal conceito acerca da ficção camiliana muito se deve em função da essencialidade passional atribuída pela crítica tradicional à obra do escritor de São Miguel de Seide, "aquela em que narração e narrado são conduzidos pelo império das paixões" (BUESCU, 1997, p. 366).

Entretanto, ao nos atermos à leitura de alguns exemplares deste cânone, percebemos que novas perspectivas podem ser adotadas no que concerne à análise crítica acerca do amor na ficção camiliana, um sentimento que pode não ser exatamente espontâneo ou autêntico, mas sim um desejo mimético, fomentado por um terceiro elemento, seja ele externo ou interno à narrativa. Para entendermos como se processa a psicologia do desejo em algumas personagens camilianas, procurando evitar a reincidência em lugares comuns sempre conferidos à obra de Camilo, faz-se necessária uma breve conceituação teórica.

Segundo René Girard, em Mensonge Romantique et Vérité Romanesque (1961). Segue a tradução do excerto: “O homem é incapaz de desejar por si próprio: é necessário que o objeto de seu desejo the seja designado por um terceiro. (...) Nós nos cremos livres (...) Em verdade, nós somente escolhemos os objetos já desejados por um outro (...).” (GIRARD, 1961, p. 07)². Desta forma, temos que a dinâmica humana do desejo estabelece-se de forma triangular, ou seja, um sujeito somente define seu objeto de desejo a partir da sugestão de um terceiro elemento, a idéia girardiana da existência incontornável de um mediador: “(...) existe um mediador que sugere o desejo entre o sujeito e o objeto" (GIRARD, 1961, p. 16) ${ }^{3}$. O conceito de mediação inerente ao desejo triangular pode ser transposto literariamente de dois modos, interno ou externo à ação romanesca. A presença de um rival ou empecilhos pessoais ou sociais à concretização do desejo são exemplos de mediação homodiegética. Já o desejo fomentado por modelos estéticos adquiridos fora da contingência narrativa é o clássico modelo de intervenção heterodiegética, como a célebre personagem de Flaubert, Emma Bovary, que somente anseia por aquilo que as heroínas românticas igualmente almejam (GIRARD, 1961, p. 18). Assim posto, de acordo com a

\footnotetext{
${ }^{2}$ Segue o excerto referente à tradução de própria lavra: "L’homme est incapable de désirer par lui seul: il faut que l'objet de son désir lui soit désigné par un tiers. (...) Nous nous croyons libre (...). En réalité nous ne choisissons que des objets déjà désirés par un autre (...).” (GIRARD, 1961, p. 07)

${ }^{3}$ Segue o excerto referente à tradução de própria lavra: “(...) il y a un médiateur qui suggère le désire entre le sujet et l'objet" (GIRARD, 1961, p. 16)
} 
perspectiva de Girard, o desejo humano é sempre triangular, ativado por um modelo a ser imitado, nada espontâneo, um desejo mimético, portanto. Vejamos, então, como essa dinâmica está disposta na ficção camiliana, por meio de duas obras em que a discussão acerca deste tema parece ser uma das questões fundamentais.

Em 1856, vêm à luz dois romances seqüenciais de Camilo Castelo Branco: Onde está a Felicidade? e Um Homem de Brios, títulos que iniciam a chamada Trilogia da Felicidade, encerrada alguns anos mais tarde, em 1863, com Memórias de Guilherme do Amaral. No primeiro deles, começam a ser narradas as venturas e desventuras do jovem casal Guilherme do Amaral e Augusta, ele um rico proprietário de Beira Alta, sedutor incorrigível e excêntrico - uma "vítima dos romances" (CASTELO BRANCO, 1970, p. 46) românticos que incessantemente lê e ela uma pobre e órfã costureira de suspensórios do Porto. O período que compreende o momento em que se conhecem até aquele em que os protagonistas tornam-se amantes é de extrema relevância para o presente estudo.

Nas primeiras páginas do romance, Guilherme do Amaral, depois de freqüentar bailes da alta sociedade portuguesa, que só fizeram aumentar seu tédio diante da existência, vaga sem destino pelas ruas do Porto até chegar à rua dos Armênios. Nesse momento, Guilherme ouve uma voz feminil a chorar: a mãe de Augusta acabara de morrer. O protagonista aproxima-se do humilde casebre e se depara com uma cena verdadeiramente trágica, provavelmente muito semelhante àquelas que leu em seus romances: uma pobre moça desespera-se diante do corpo inanimado de sua mãe. Guilherme gentilmente oferece ajuda e, depois, sai da casa

(...) vivamente impressionado. Era um quadro novo, uma excitação a sentimentos que vibravam pela primeira vez. Os olhos da alma iam-lhe todos preocupados no lance angustioso duma filha, abraçada ao cadáver da mãe, seu arrimo partido num instante, olhando em redor, para contemplar-se ouvida pelo silêncio do desamparo. Se, todavia, pudesse abstrair os olhos do espírito daquela cena, e fixar os do rosto da filha dessa mulher, teria visto uma linda rapariga. (CASTELO BRANCO, 1970, p. 89-90)

Nesse sentido, percebemos que o fator inaugural que faz com que Guilherme se aproxime de Augusta é a tragicidade da cena por ela protagonizada e é este mesmo componente que o leva a criar um vínculo com a personagem. É o trágico, aquilo que se assemelha ao romanesco, o propulsor de seu interesse, a beleza de Augusta, de início, nem ao menos é notada: a mediação 
externa, literária, começa a instaurar-se. Em seguida, fascinado pelo quadro presenciado, Guilherme passa a freqüentar a casa da costureira e vemos seu desejo pela moça surgir na medida em que o rico rapaz nela vislumbra um ser angelical, somente antes visto em seus livros: a jovem órfã é meiga, cora facilmente, não demonstra ganância por dinheiro e nunca teve nenhum relacionamento. Guilherme, encantado, julga “(...) descobrir naquela mulher uma coisa especial, um instinto não vulgar (...)" (CASTELO BRANCO, 1970, p. 99). Em suma, o protagonista se interessa por Augusta, pois ela parece corresponder ao modelo estético de "mulher-anjo": o desejo de Guilherme é mediado, externamente à ação romanesca, por modelos literários, um desejo mimético, que não corresponde a um amor cuja origem lhe seja interna.

Outros mediadores podem ainda ser notados, desta vez internos à diegese, dois empecilhos à relação amorosa que só fazem nutrir o desejo de Guilherme: a presença de um rival, o primo tecelão de Augusta, Francisco, sempre por perto e lhe propondo casamento, e a própria Augusta, que nunca cedera à nenhuma investida e tampouco se mostra disposta, em nome de sua honra, a fazê-lo. Nesse momento de expressa rivalidade, fomentada por Francisco e pela própria protagonista ao se tornarem impedimentos à relação, Guilherme tem seu desejo insuflado pela vaidade, qualidade esta que paulatinamente torna-se sua característica mais determinante: "Amaral cedia, neste momento, ao orgulho, e perguntava-se se não era aquela a sua primeira conquista gloriosa" (CASTELO BRANCO, 1970, p. 102).

Com efeito, a vaidade é um dos sentimentos que mais propiciam o surgimento do desejo mimético: “O vaidoso não pode extrair seus desejos de seu próprio ser; ele os empresta de outro. [...]. Para que um vaidoso deseje um objeto, basta lhe convencer que este objeto já é desejado por um terceiro ao qual se atribui certo prestígio." (GIRARD, 1961, p. 19 e 20). ${ }^{4}$. Assim sendo, podemos inferir que Guilherme sofre dupla mediação, externa e interna. Respectivamente, enquanto "vítima dos romances" (CASTELO BRANCO, 1970, p. 46) mimetiza os moldes literários românticos e deseja a costureira, uma provável "mulher-anjo", e, por sua vaidade atávica, deseja aquilo que já é almejado por Francisco e que ninguém nunca conseguiu conquistar. Disposto desta forma duplamente mimética o desejo de Guilherme, pensemos, a partir deste momento, como se constitui o de Augusta.

\footnotetext{
${ }^{4}$ Segue a tradução referente à tradução de própria lavra: "Le vaniteux ne peut pas tirer ses désirs de son propre fonds; il les emprunte à autrui. (...) Pour qu'un vaniteux désire un objet il suffit de le convaincre que cet objet est déjà désiré par un tiers (...)." (GIRARD, 1961, p. 19 e 20)
} 
Sabemos que a jovem dá mostras de não estar disposta a casar-se com Francisco nem de corresponder ao assédio de Guilherme. Entretanto, sabemos que ela finda por se tornar amante deste último, negando todos os conceitos de honra que diz ter. Resta-nos tentar entender o motivo que a levou a preterir uma situação estável e legítima com o primo e aderir a um relacionamento "leviano" com o de Beira Alta. Durante as visitas de Amaral, por vezes, o tecelão aparece para ver a prima. Em uma clara contraposição de personagens, não explícita, mas inegavelmente sugerida, estão postos Guilherme e Francisco. Em uma cena muito elucidativa, encontramos Augusta contando a Amaral que mandara rezar missas em memória de sua mãe com o dinheiro dado por ele. Nesse instante, torna Francisco: “-É boa maneira de gastar dinheiro...- disse o fabricante ironicamente." (CASTELO BRANCO, 1970, p. 99) Guilherme e Augusta reagem reativamente. Ele afirma:

-Eu acho bem empregado o dinheiro que nos serve de suavizar a saudade, desempenhando a obrigação em que os vivos ficam com as pessoas, que nos morreram. Fez a menina muito bem.

Augusta baixou a cabeça com um certo ar de inteligência. Francisco abrira a boca ao arrazoado de Guilherme, sinal significativo de que o não entendera. (CASTELO BRANCO, 1970, p. 99-100).

Assim posto, percebemos a clara distinção entre as personagens e a evidente reprovação de Augusta para com a atitude pouco polida de Francisco e a óbvia aceitação diante da crítica tecida por Guilherme. Em suma, Augusta, por quatro anos, recusou a corte de seu primo, um trabalhador humilde, um tanto obtuso e grosseiro no trato com as pessoas. Este comportamento rude é repudiado pela costureira que, mesmo sendo igualmente uma mulher do povo, demonstra destreza e elegância socialmente. Por exemplo, diante de uma atitude disparatada do tecelão, Augusta não se contém: "-Se tu te calasses, fazias bem melhor...- disse Augusta muito envergonhada, e com um gesto natural de aborrecimento, que agradou muito a Guilherme (...)." (CASTELO BRANCO, 1970, p. 101). Logo em seguida, afirma o narrador: “(...) O fabricante, se dissesse bocadinhos de ouro, seria sempre, ao pé de Guilherme, um grosseirão. Compará-lo (...), ouvi-lo, depois do hóspede, era para Augusta uma quase vergonha de ter tal parente" (CASTELO BRANCO, 1970, p. 106). E é por estes tempos que vemos a costureira começar a ceder ao rico mancebo. 
Sob este prisma, podemos supor que Augusta, adotando uma postura de absoluta negação por Francisco, passa a desejar Guilherme, provavelmente porque este é o contraponto daquele: Amaral é elegante, de palavras suaves, culto, rico, tudo aquilo que o tecelão nunca foi. Em síntese, após a análise do início da relação dos protagonistas, fica-nos a impressão de que Augusta tem seu desejo despertado por Guilherme, pois este é a personificação inversa de Francisco, um processo de mediação interna bem peculiar. É como se o fabricante inconscientemente e por contraste mediasse o desejo de Augusta, que segue a mesma lógica mimética de Girard, apenas de modo contrário: por recusar o modelo de Francisco, Augusta almeja seu inverso, Guilherme, uma espécie de desejo antimimético.

Nesse sentido, talvez seja este o motivo pelo qual a costureira finda por aceitar uma relação instável com Guilherme, contrariando seus conceitos de honra: “(...) -Eu quero viver com honra...e, quando sair daqui, há de ser para entrar na igreja" (CASTELO BRANCO, 1970, p. 146). Uma vez que o primo sempre lhe ofereceu uma união estável pelo matrimônio, Augusta, ao recusar tudo o que vinha de sua parte, repeliu também isto, mesmo ainda tendo esperanças de um dia se casar com Guilherme. Este, por seu turno, deixou explícita sua apreciação acerca deste assunto e o quão difícil seria dissuadi-lo: “(...) - Pois a menina persuade-se que só o casamento faz a felicidade e a honra duma mulher? Está muito enganada, e tem razão, porque não sabe nada do mundo. A mulher casada não é feliz quando se não conforma com as inclinações do marido, e vive num inferno de portas a dentro. (...)" (CASTELO BRANCO, 1970, p. 148-149).

Dessa forma, Augusta e Guilherme desejam-se mutuamente, cedem ao impulso e tornamse amantes. Entretanto, mais rapidamente para um do que para outro, o desejo encontra seu fim na saciedade. Três dias depois de montada uma casa no Candal, Guilherme já se sente entediado e volta a freqüentar a sociedade. A jovem percebe o paulatino distanciamento de seu companheiro e desespera-se, em vão. Amaral já está em busca de algo ou alguém que o tire, ainda que momentaneamente, de seu fastio atávico e este alguém já não pode ser Augusta, um desejo satisfeito. Quando o novo objeto de desejo de Amaral é encontrado, a costureira é abandonada. Mais uma vez, o jovem sofre um duplo processo de triangulação de seu desejo: Leonor, uma prima, é escolhida, pois parece corresponder ao estereótipo romântico de "mulherfatal", uma mediação externa, e também porque esta já tem um pretendente, um rival, mediador interno, que a vaidade de Guilherme não deixa de notar. Mesmo assim, Augusta parece nunca 
deixar de suspirar pelo de Beira Alta, mesmo abandonada e grávida, seu desejo nunca arrefece, talvez por ter sido ela a preterida.

Os sucessos prosseguem: antes por "orgulho" (CASTELO BRANCO, 1970, p. 297) do que exatamente por "virtude" (CASTELO BRANCO, 1970, p. 296), como faz questão de enfatizar o narrador, Augusta volta para a rua dos Armênios, passa a sua gestação reclusa a fim de que ninguém perceba o seu estado, sempre ao lado de Francisco e de uma outra personagem, amigo também de Amaral, o jornalista. Entretanto, o filho do mal-fadado relacionamento nasce morto. Sendo necessário enterrá-lo, o assoalho da humilde casa da costureira parece ser a única solução. Francisco abre uma vala e, ao fazê-lo, encontra uma fortuna que havia sido escondida por João Antunes da Mota, personagem que figura no prólogo da obra. Francisco propõe casamento à prima, que acaba por ceder. Por fim, eles se tornam os barões de Amares.

Ao tomar conhecimento do destino de Augusta, Guilherme não se conforma com o fato de não ser mais necessário à felicidade da mais nova baronesa do Porto e indaga ao seu confidente jornalista se ela ainda fala no antigo amante:

\footnotetext{
-Essa pergunta é vaidosa. Não, nunca me falou em ti. (...)

-Considera-a feliz?

- É feliz.

-Não posso acreditar-te. Aquela mulher deve ansiar por uma alma.

- Como a tua naturalmente... Deixa-me dar a mais santa das gargalhadas... (...) Não te aflija esse zelo do bem-estar de Augusta... o teu amor-próprio pode irritar-se, mas deixá-lo. (...) (CASTELO BRANCO, 1970, p. 374).
}

Assim sendo, podemos perceber que Guilherme, insuflado por seu orgulho, componente que lhe é indissociável, não aceita a felicidade da ex-amante, por não se conformar em não mais ser necessário. Está posto o mote para o segundo romance: Guilherme do Amaral, Um Homem de Brios, terá novamente seu desejo acionado pela mola mimética da vaidade (GIRARD, 1961, p. 19 e 20) e sairá em busca de, mais uma vez, conquistar Augusta, agora casada com Francisco, um rival a ser aniquilado.

Com efeito, durante a seqüência de Onde está a Felicidade?, vemos o incessante embate dos protagonistas, ele tentando seduzi-la e esta esquivando-se de toda forma possível. Vale notar que existe uma constante discussão acerca da verdadeira motivação de Guilherme: seria amor ou pura vaidade, desejo mimético satisfeito com a conquista? O narrador é enfático ao optar pelo 
orgulho, afinal enuncia a história de Um Homem de Brios, e não de um homem apaixonado. Em dado momento, a voz narrativa afirma: "O coração! Pois é crível a existência de coração no peito deste homem?!” (CASTELO BRANCO, 1967, p. 14). Em outro episódio, assegura: “A razão [o] condenara [pelo abandono], e Guilherme do Amaral apelou para o tribunal da vaidade." (CASTELO BRANCO, 1967, p. 17). O jornalista, seu confidente, é de igual opinião: “(...) -Meu amigo, o teu sentimento cheira-me a capricho de poesia sobre-posse..." (CASTELO BRANCO, 1967, p. 150).

Até mesmo Guilherme não consegue persuadir-se por completo de que seu sentimento é mais puro e profundo. Por exemplo, já na metade do romance, ficamos sabendo que Guilherme escreve seis cartas para Augusta, epístolas nas quais assegura estar arrependido de tê-la abandonado. Desse modo, resta a impressão de que o jovem afirma seu "amor" pela baronesa de Amares. No entanto, nestes mesmos dias em que compõe as cartas, Guilherme freqüenta os bailes da alta sociedade portuguesa. Em um deles, durante uma conversa com seu amigo, assume: “(...) -São os brios que se bebem no leite, e ficam ilesos no coração, perdidos todos os outros sentimentos grandes." (CASTELO BRANCO, 1967, p. 164). Nem o próprio Amaral consegue se convencer de que seu sentimento por Augusta é elevado, é, muito antes de ser um amor idealizado e genuíno, um desejo mediado pela vaidade, orgulho que o faz querer a antiga costureira de toda forma: "-Veremos...- murmurou Guilherme do Amaral ferido no orgulho." (CASTELO BRANCO, 1967, p. 151).

De forma similar, o possível “amor” de Augusta também é problematizado. Vimos que a protagonista, no romance inaugural, não teve seu desejo por Guilherme satisfeito, foi este quem deu fim à relação. Em Um Homem de Brios, Augusta, ao descobrir o renovado interesse do examante, oscila entre ceder ou não à tentação de ser novamente amásia de Guilherme. No entretanto, várias facetas do sentimento nutrido pela baronesa são explorados: não se sabe ao certo se ela "ama" Guilherme, se seria um sentimento "religioso" de perdão por quem lhe fez tanto mal, se consistiria em um afeto decorrente da gratidão por quem lhe proporcionou enriquecimento cultural, ou se, ainda, Augusta teria, subliminarmente a sua afeição, o desejo de se vingar de Guilherme: "vontade de humilhar com uma generosidade soberba o homem, cujas esmolas repelira." (CASTELO BRANCO, 1967, p. 37). Augusta permanece a mesma personagem orgulhosa que deixou o Candal em Onde está a Felicidade?. 
Como podemos perceber, estas narrativas muito versam acerca da psicologia do desejo atuante nas personagens, impulso triangular por princípio, consoante Girard, um tema muito antes humano do que propriamente relativo a uma escola literária. Todavia, estes romances de matéria atemporal possuem um desfecho, nas derradeiras páginas de Um Homem de Brios, não condizente a todo este desenrolar analítico: Augusta morre e Guilherme do Amaral enlouquece, tragicidade tipicamente romântica. Entretanto vejamos.

No paratexto inicial da segunda obra, Camilo nos lança a seguinte reflexão a respeito da recepção crítica de Onde está a Felicidade?:

O certo é que desses poucos compradores do meu romance conheço dois que me fizeram o favor de o ler até o fim, com a louvável intenção de me dizer que o romance não acaba bem, porque, além de... tendo em vista..., sendo certo que..., atendendo a ..., o romance não acaba bem.

Das razões que meus benévolos censores aduziram, colhi: $1^{\circ}$ que o romance acaba mal; $2^{\circ}$ que estava a pouco em fazê-lo acabar bem; $3^{\circ}$ que a baronesa de Amares não devia ficar viva, ou pelo com juízo, visto que eu podia matá-la, ou por grande favor, enlouquecê-la; $4^{\circ}$ Guilherme do Amaral não devia fazer o que faz muito boa gente - seduzir, esquecer, comer, beber, dormir, e acordar para seduzir, esquecer, comer, etc.; $5^{\circ}$ eu devia dizer que fim que tiveram a baronesa, o barão, o Amaral, o filho adotivo da costureira, a prima do Amaral, e o poeta. Os assassinos queriam que tudo isso morresse desde 1849 a 1855, em que eu, a pedido dum arquivista de sucessos contemporâneos, escrevi um romance." (CASTELO BRANCO, 1967, p. 07)

Nesse sentido, Camilo nos mostra que seus coetâneos não buscavam em um romance "sucessos contemporâneos", nem "uma exatidão dos costumes" (CASTELO BRANCO, 1967, p. 08), a vida tal qual ela é e Camilo e gostaria de mostrar" ${ }^{5}$ mas sim fabulações de "(...) arrepiar os cabelos, e espremer lágrimas nos olhos rebeldes (...)"(CASTELO BRANCO, 1967, p. 08). Ansiavam, enfim, enredos passionais e, se possível, trágicos: um suicídio ou demência em Augusta, por exemplo, faria o romance acabar bem. Dessa maneira, constatamos que o autor, levando em conta sua condição de escritor profissional, encontrava-se diante da complexa questão de conciliar, em um único romance, sua vertente de romancista analítico social em uma narrativa que deveria se concluir de modo a agradar o Mercado Editorial da época, ou seja, de forma, ao menos aparentemente, passional. Em uma leitura mais superficial, toda a conceituação acima tecida acerca do conceito mimético que move as personagens, pode muito bem ser lida em

\footnotetext{
${ }^{5}$ Sobre este tocante, Camilo afirma: "Eu desejo escrever de modo que o meu leitor (...) possa dizer: 'a vida é isto"”. (CASTELO BRANCO, 1967, p. 9).
} 
função de um mero enredo passional: “(...) Camilo trata dramaticamente um caso de sedução, explora a angústia da seduzida e os remorsos do sedutor" (COELHO, 1946, 295, v. I). E, se também lido de modo desatento, o desfecho da presente obra pode ser tomado como passional. Passemos, então, a conclusão dos sucessos.

Guilherme, após sofrer um acidente, é socorrido por Francisco. Na mansão dos Amares, Augusta não suporta saber que Amaral poderia ter morrido e decide não mais resistir às investidas do eterno sedutor. Contudo, Guilherme já não pode mais assentir que ela traia seu marido, quem o salvou da morte. Privados, definitivamente, de ficarem juntos, visto que o orgulho de Guilherme é imensamente mais forte que qualquer outro sentimento, este se recolhe em sua propriedade de Beira Alta até a demência e Augusta, quando fica sabendo que Amaral enlouqueceu, finalmente alcança a tão sonhada morte por tuberculose. “(... ) [S]angue, muito sangue (...)"(CASTELO BRANCO, 1967, p. 230), elemento, segundo o narrador camiliano, sine qua non para a sua imortalidade.

Desse modo, percebemos que Camilo conclui seu romance de forma apenas, aparentemente, passional, pois a tragicidade do desfecho somente se deu, em primeiro lugar, porque mercadologicamente não poderia deixar de existir, segundo a advertência preliminar, e, uma vez imprescindível, ela foi advinda do orgulho de Guilherme do Amaral e não de um possível amor. Um desenlace que, muito antes de afirmar a passionalidade, o amor-paixão que tudo vence ou destrói, mostra que estes sentimentos são incompatíveis com a sociedade portuguesa oitocentista, ambiente propício para o orgulho, a vaidade e o desejo, mas infecundo para afeições abnegadas.

Em se tratando da materialista sociedade portuguesa e sua incompatibilidade junto a sentimentos elevados, resta-nos ainda levantar mais um elucidativo exemplo de desejo mimético enunciado na trama, um que pode nos conduzir a mais uma chave de interpretação da psicologia do desejo presente nestas obras. Tanto no romance inaugural quanto em sua seqüência, temos capítulos inteiros dedicados à apreciação de bailes da alta sociedade portuense. Neles encontramos moças casadoiras e jovens rapazes em busca de um par. Contudo, vale notar o principal elemento que faz com que casais queiram se formar. Em Onde está a Felicidade?, quando Guilherme passa a freqüentar estes encontros, temos a seguinte fala percorrendo pelo salão: 
-Dizem que é rico - murmurava ao ouvido de sua amiga uma interessante menina de olhos lânguidos, tez macilenta, e sorriso melancólico.

-Já ouvi dizer - respondeu a prima.

-Ouviste!? E será muito rico?

-Penso que sim; meu tio conselheiro falou em trezentos mil cruzados.

- Sim?! Não terá namoro? (CASTELO BRANCO, 1970, p 55-56.)

Em seguida à constatação de um rico mancebo em meio ao baile, encontramos ao menos três personagens femininas, Cecília, Margarida e Francisca, lutando para conquistar a afeição de Guilherme e dizendo-se perdidamente apaixonadas: a partir do momento em que se fez notável a fortuna de Guilherme, uma a uma caiu de amores pelo de Beira Alta, um desejo mimético mediado internamente pelo dinheiro. Nesse sentido, podemos inferir que a alavanca inicial do desejo destas figuras é o capital possuído pelo protagonista, sem o qual talvez nem fosse notado, ou causasse tanto furor repentino. Vale ressaltar que até mesmo em insuspeitos terrenos, jovens que parecem corresponder ao estereótipo de uma heroína romântica, "menina de olhos lânguidos, tez macilenta, e sorriso melancólico", a motivação inaugural de seus desejos é pecuniária.

Seguindo este viés crítico de análise social e psicológica das personagens que figuram na trama, em Um Homem de Brios, temos um caso muito semelhante. Em um dos bailes freqüentado por Amaral, vemos uma jovem órfã, Eulália, sendo cortejada por um séqüito de pretendentes, todos a desejando ferozmente, anseio mediado por seu alto poder aquisitivo, "os cento e cinqüenta contos" (CASTELO BRANCO, 1967, p. 119). A este respeito, o jornalista afirma em tom mordaz a Guilherme: "O Porto tem sete homens que baterão a setenta portas onde houver dinheiro, pedindo um dote (...). Estes sete homens estão diante de nós, suspeitosos uns dos outros, observando-se de través, com o diabo do ciúme mercantil a devorá-los." (CASTELO BRANCO, 1967, p. 112-113.). Como já notou Óscar Lopes, são "bailes da alta burguesia (...) [que] funcionam como feiras para casamento por dinheiro" (LOPES, 1991, p. 47).

Sob este prisma crítico social, já lançado por Camilo antes mesmo do primeiro encontro dos protagonistas, podemos ainda vislumbrar que o papel mediador do dinheiro também cumpre uma função de destaque na história de Augusta e Guilherme. Isto porque, sem sua condição abastada, talvez Amaral não conseguiria se diferenciar de Francisco; sem o dinheiro a engendrar uma culta educação e a suster sua distinta elegância, provavelmente o de Beira Alta não fosse tão inversamente proporcional ao tecelão. Se Guilherme fosse trabalhador e tivesse, por exemplo, que subsistir de seu ofício, a narrativa tomasse rumos bem dessemelhantes. Nesse sentido, 
percebemos que o dinheiro constitui relevante papel mediador do desejo na sociedade portuguesa oitocentista, que, como já dito, configura-se enquanto ambiente nada propício a sentimentos enaltecedores, como um amor altruísta ou um afeto desinteressado.

Em síntese, a partir da análise feita, podemos perceber que a psicologia do desejo nas personagens camilianas estudadas possui uma dinâmica mimética, na qual a vaidade e o "ciúme mercantil" (CASTELO BRANCO, 1967, p. 113) exercem importante função mediadora. Seguindo este raciocínio, vislumbramos na ficção camiliana outra perspectiva de leitura, consoante a qual o amor, enquanto sentimento genuíno e profundo, não encontra ambiente promissor. Como visto, encontramos o "império" de paixões pouco elevadas, como o orgulho e o desejo, que, em geral, são escassamente detectadas na obra de Camilo e que revelam uma faceta do escritor mais preocupada com sentimentos humanos atemporais, que independem da moda romântica que tanto lhe é imputada sem maiores mesuras. Um autor que, mesmo sob a égide mercadológica romântica do amor puro, profundo e eterno, consciente ou inconscientemente, não obliterou o processo triangular do desejo humano, componente que imprime uma universalidade ao cânone do escritor de São Miguel de Seide ainda pouco notada e que se faz imprescindível explorar.

\section{Referências Bibliográficas}

BUESCU, Helena Carvalhão (coord.). Dicionário do Romantismo Literário Português. Lisboa: Caminho, 1997.

CASTELO BRANCO, Camilo. Onde está a Felicidade?. Lisboa: Parceria A. M. Pereira, Lda, 1970.

Um Homem de Brios. Lisboa: Parceria A. M. Pereira, Lda, 1967.

COELHO, Jacinto do Prado. Introdução ao Estudo da Novela Camiliana. Coimbra: Editora Atlântida, 1946, v. I.

GIRARD, René. Mensonge Romantique et Vérité Romanesque. Paris: Grasset, 1961.

LOPES, Óscar. “Claro-escuro camiliano”. In: Colóquio-Letras. Nº 199, Janeiro-Março, 1991. 